\title{
The Construction and Analysis of the Evaluation System of Double Performance about Farmer Cooperatives
}

\author{
Huimin SHAO ${ }^{1, a}$, Yang $\mathrm{Xu}^{1, \mathrm{~b}}$, Lingling $\mathrm{Ma}^{1, \mathrm{c}^{*}}$ \\ ${ }^{1}$ School of Economics and management, Yunnan Normal University, KunMing, Yunnan, China \\ a562859539@qq.com, b $982690807 @ q q . c o m, ~ c 1261682062 @ q q . c o m$ \\ ${ }^{*}$ Corresponding author
}

Keywords: Farmer Cooperatives, Double Performance, Evaluation System.

\begin{abstract}
Based on the related literature and the stakeholder theory, this paper analyzes the reliability and validity of the double performance by using the methods of questionnaire investigation and quantitative analysis. By weighting the analytic hierarchy process (AHP), calculating with the method of the weights and efficacy coefficient, and validating through the data of the 19 farmers cooperatives of Lancang, Luquan, and Changning, this paper concludes that the cooperative evaluation result is consistent with actual situation basic conclusions. The results can be used for scientific responses and solutions to improve cooperative performance, thus providing a basis for managers to guide and support the development of farmer cooperatives more scientifically.
\end{abstract}

\section{Introduction}

The Communist Party and government have always attached great importance to the development of China's farmer cooperatives[1]. From 2013 to 2017, developing various forms of farmer cooperatives has been specifically proposed and emphasized in the Central Document No. 1 for the five consecutive years, and the farmer cooperatives have continued to develop in depth.

Since 2000, Chinese farmer cooperatives have entered in a stage of rapid development. According to the statistics of the commercial administration, by the end of 2015, the number of farmer cooperatives registered in law had reached 1.513 million (increase 13.34 times compared of 2008), and the number of farmers' households entering in farmer cooperatives breakthrough 100 million, accounting for $42 \%$ of the total households. On the whole, although the development of farmer cooperatives is swift and fierce, in terms of the contribution of cooperatives to farmer households' income, the performance of cooperatives, especially economic performance, remains to be improved. For example, the operating income of farmers cooperatives in Yunnan Province was 7.62 billion yuan in 2015 , increasing $17 \%$ over the previous year and the growth momentum was relatively fast, while it only accounted for $1 \%$ of total revenue. It can be said that China's farmer cooperatives are facing a critical period from quantitative growth to quality improvement, desiring to strengthen internal governance to improve its performance.

The existing research failed to effectively explain the mechanism of improving of the performance of farmer cooperatives. The key to this is that the performance evaluation analysis of cooperatives is not thorough enough[2,3]. However, performances have a subjective feeling to a certain extent and it will be difficult to measure[4]. At present, in the existing research literature both at home and abroad, there are relatively few contents about the complete measurement performance of farmer cooperatives. In addition, in view of the unique characteristics of the community's uniqueness of embedding and the dominant position of the core members in the cooperatives in our country, at the same time taking the existing international performance indicators system into account, we will fully consider the characteristics of Chinese farmer cooperatives, using stakeholder theory, questionnaire survey, quantitative analysis and other methods to build a performance evaluation index system for farmer cooperatives that conforms to Chinese conditions. 


\section{The evaluation index system framework of "dual performance"}

The indicators of economic performance of cooperatives include the increase in per annual net income of members, the overall upward trend in the return interest of members, the proportion of agricultural products that cooperatives selling for members, etc. after joining cooperatives[5]. Non-economic performance includes whether members have the idea retiring from the society, whether the number of cooperatives is increasing, whether cooperatives own the brand of their products, etc. See Table 1 for details.

Table 1. Farmer cooperatives "dual performance" evaluation index and its components system

\begin{tabular}{c|c|l}
\hline Target layer & Guidelines layer & \multicolumn{1}{c}{ Indicator layer } \\
\hline \multirow{4}{*}{ Performance } & \multirow{2}{*}{\begin{tabular}{l} 
Economic Performance \\
\cline { 2 - 3 }
\end{tabular}} & $\begin{array}{l}\text { After joining the cooperative, my per annual net income } \\
\text { increased X1 }\end{array}$ \\
\cline { 2 - 3 } & $\begin{array}{l}\text { The number of profit returns I get is generally on the upward } \\
\text { trend X2 }\end{array}$ & A higher proportion of agricultural products sold for members X3 \\
\cline { 2 - 3 } & $\begin{array}{c}\text { Non-economic } \\
\text { performance }\end{array}$ & I currently have no idea of retreat Y1 \\
\cline { 2 - 3 } & The number of people joining the cooperative increases Y2 \\
\cline { 2 - 3 } & We have our own brand of products Y3 \\
\hline
\end{tabular}

\section{Inspection and weight determination of "dual performance" scale of farmer cooperatives}

\subsection{Reliability and validity test of performance scale}

\subsubsection{Sample description}

From August 2015 to October 2016, the author interviewed and interviewed 25 farmer cooperative members in the four counties of Jianshui, Handan, Luquan, and Changning in Yunnan Province.Questionnaire survey combines random sampling and typical sampling methods for farmer cooperatives, collecting total of 452 samples. Taking into account the completeness of the questionnaires that the data of six cooperatives in Jianshui and Changning County were not used, we collected a total of 367 valid samples. In part, the effective recovery rate was $81.4 \%$.

\subsubsection{Variables and their metrics}

In order to test the rationality of the indicator system again, the author used SPSS22.0 and AMOS22.0 to analyze its reliability and validity. It can be seen from the analysis results that the value of the variable Cronbach's $\alpha$ is higher than the standard 0.7, indicating that the research variable is relatively good in terms of reliability. The relevant indicators calculated by the confirmatory factor analysis method meet the standards and requirements. It shows that the variables are also very good in terms of construct validity[6]. From the perspective of social sciences, the criterion for determining whether factor loads effective is its absolute value greater than 0.4. The cooperatives' performance in this paper conforms to this principle. According to the analysis of all factor loads, all variables are higher than 0.5 . This indicates that each factor has very outstanding explanatory power, possesses a good structural validity, and the survey statistics are relatively good. It will help the next step in the research.

\subsection{Calculation of index weight based on AHP method}

This paper consists of four college teachers, an expert from the Provincial Department of Agriculture, and a president of a farmer cooperative. In the expert scoring stage, especially the establishment of the judgment matrix, subjectiveness will be more prominent. Therefore, in order to avoid the seriousness of the problem and reduce the impact, it is optimized by using the Delphi method. According to the survey data, please see the table below. 
Table 2 .Performance indicator weights and consistency test

\begin{tabular}{|c|c|c|}
\hline $\begin{array}{l}\text { First-level } \\
\text { indicators }\end{array}$ & Second-level indicators & Third-level indicators \\
\hline \multirow{6}{*}{ Performance } & Economic performance & $\begin{array}{l}\text { After joining the cooperative, my per annual net income increased } \\
(0.4)\end{array}$ \\
\hline & 0.8333 & $\begin{array}{l}\text { The number of returns I received returned to an overall upward } \\
\text { trend }(0.4)\end{array}$ \\
\hline & & $\begin{array}{l}\text { A higher proportion of agricultural products sold to members } \\
(0.2)\end{array}$ \\
\hline & $\begin{array}{l}\text { Non-economic } \\
\text { performance }\end{array}$ & I currently have no idea of retreat $(0.1429)$ \\
\hline & 0.1667 & The number of people joining the cooperative increases $(0.5714)$ \\
\hline & & We own the brand of our own products $(0.2857)$ \\
\hline
\end{tabular}

Note: The judgment matrix $1 \mathrm{CI}=0, \mathrm{RI}=0$, and $\mathrm{CR}=0$; the judgment matrix $2 \mathrm{CI}=0, \mathrm{RI}=0.58$, and $\mathrm{CR}=0$; the judgment matrix $3 \mathrm{CI}=0, \mathrm{RI}=0.58$, and $\mathrm{CR}=0$, all passed the consistency check.

\section{Summary}

In the process of performance evaluation of farmer cooperatives, each specific indicator represents an evaluation analysis perspective. Different indicators require their own units of measurement. In order to further compare the quantities of these different units, special treatment measures must be taken for the original data. This paper summarizes the analysis process, mainly based on the relevant content in the "Rules for the evaluation of state-owned capital performance," and uses the efficacy coefficient method to convert the impact of data on different unit to obtain a uniform value[7]. Calculation formula: The single item score of a specific indicator is the actual score of the indicator minus the minimum value of the indicator divided the highest value of the indicator minus the lowest value of the indicator, than the resulting data is multiplied by 40 and plus 60 . At last, the resulting index value is in the range of 60-100. In the range. At the same time, the scores of each indicator are multiplied by the corresponding weights, and the results sorting obtained by adding together are the performance scores of agricultural cooperatives, as detailed in the following table.

Table 3. Performance values and ranking of cooperatives

\begin{tabular}{|c|c|c|c|}
\hline $\begin{array}{c}\text { Survey } \\
\text { area }\end{array}$ & Cooperatives & $\begin{array}{c}\text { Performance } \\
\text { values }\end{array}$ & Ranking \\
\hline \multirow{3}{*}{ Lan Cang } & Hongfeng Coffee & 64 & 13 \\
\hline & Guangyuan Tea & 65 & 12 \\
\hline & Zhixing beef & 70 & 9 \\
\hline \multirow{6}{*}{ Lu Quan } & Zhong Fu flue-cured tobacco & 68 & 10 \\
\hline & Yunlong planting & 65 & 12 \\
\hline & Baiji planting & 74 & 8 \\
\hline & Forest Industry Development & 63 & 14 \\
\hline & Herbal cultivation & 67 & 11 \\
\hline & Planted under Xinhelin & 65 & 12 \\
\hline \multirow{8}{*}{ Changning } & Linfuyuan Forest Animals & 77 & 7 \\
\hline & Hewei Agricultural Machinery & 79 & 6 \\
\hline & Shed fresh mushrooms & 89 & 1 \\
\hline & Zhenqiang thin bubble walnut & 88 & 2 \\
\hline & Lvyuan Herbal Planting & 80 & 5 \\
\hline & Hewei Ancient Tree Tea & 87 & 3 \\
\hline & Wenyin Capricorn & 87 & 3 \\
\hline & Kejie Jia cuisine vegetables & 85 & 4 \\
\hline
\end{tabular}




\begin{tabular}{|c|c|c|} 
Kass Chia breeder pig & 80 & 5 \\
\hline $\begin{array}{c}\text { Township Fuhua Rongxin Bubble } \\
\text { Walnut }\end{array}$ & 74 & 8 \\
\hline
\end{tabular}

It is not difficult to see that the performance evaluation results of the selected cooperatives are far from those of the developed provinces, but they are in line with what we have actually grasped. The evaluation results can more realistically show the actual development of cooperation and have a positive guiding effect on the future development.

\section{Acknowledgment}

This research was financially supported by the National Natural Science Foundation of China (Grant NO. 71763032), Yunnan Planning Office of Philosophy and Social Science(Grant NO. YB2017109) and Yunnan Normal University's PhD Project(2017).

The research was sponsored by NSFC project (71763032), YNPOPSS project (YB2017109), Yunnan Normal University's PhD Project(2017).

\section{References:}

[1] Ran Chinong,Huo Xuexi, Research on the Performance of Yangling Farmers' Professional Cooperatives. Economic Research Guide, vol. 26:pp.92-95,2012.

[2] Fan Yuanjiang, Yang Guizhong. Analysis of Performance Evaluation Research Paradigm of Farmers' Professional Cooperatives. Economic Review, vol. 1: pp58-61, 2011.

[3] Luo Yingling,Li Xiao,Du Xingrui, Design of Comprehensive Performance Evaluation System for Farmer Professional Cooperatives. Rural Economy, vol. 2:pp.117-120,2014.

[4] Cui Baoyu,Jian Peng,Wang Chunhui, Farmer Specialized Cooperatives:Performance Measurement and Influence Factors - A Study on the Development Path of Cooperatives. China Agricultural University Journal of Social Sciences Edition, vol. 4:pp.106-115, 2016.

[5] Cui Baoyu,Jian Peng,Liu Lizhen, Performance Decision and "Paradox" of Farmer Professional Cooperatives: An Empirical Study Based on AHP-QR.Journal of Agrotechnical Economics, vol.1:pp.109-123, 2017.

[6] Li Daohe,Chen JianghuaPerformance Analysis of Farmers' Professional Cooperatives: Based on Jiangxi Provincial Survey Data. Journal of Agrotechnical Economics, vol.1:pp. 65-75, 2014.

[7] Shao Ke,Huang Zuhui, Farmer Cooperatives Member Participation Behavior, Effect and Action Mechanism.Journal of Northwest A\&F University(Social Science Edition), vol. (6):pp.45-50, 2014. 